REVISTA DE DERECHO UNED, NÚM. 10, 2012

\title{
RESPONSABILIDAD PERSONAL Y REAL: CUESTIONES SOBRE EL ARTÍCULO 118 DE LA LEY HIPOTECARIA Y LOS PACTOS DE RETENCIÓN Y DESCUENTO DEL PRECIO EN LA TRANSMISIÓN DE FINCA HIPOTECADA
}

\author{
$M^{\mathrm{a}}$ Fernanda Moretón SANZ \\ Profesora Contratada Doctora del Departamento de Derecho Civil \\ de la UNED
}

Resumen: El artículo 118 de la Ley Hipotecaria, cuya redacción se remonta a la reforma hipotecaria del año 1944, consagró en su primer párrafo una práctica notarial consistente en la suscripción de los llamados pactos de retención en el precio de los contratos de compraventa. Estos acuerdos se concertaban para pagar la deuda pendiente del vendedor, o con la condición de destinar la parte del precio retenido al pago de una deuda que el vendedor mantenía con un tercero. La adquisición de la cosa objeto de compraventa se posponía al cumplimiento de la condición o, en su defecto, a su afianzamiento. Adicionalmente y teniendo en cuenta que el artículo 118 de la Ley Hipotecaria dio carta de naturaleza a la asunción de deudas, nos detendremos en este pacto donde se prescinde, gracias a la fórmula tipificada, del complejo procedimiento de la novación subjetiva pasiva extintiva que reclamaba la sustitución de una relación por otra nueva a la que reemplazaba. Al tiempo, este precepto ratifica la esfera del poder de disposición que conserva el sujeto pasivo del derecho de crédito garantizado con hipoteca.

Abstract: In its first paragraph, Article 118 of the Mortgage Law drafted during the mortgage system reform back in 1944- established a very common notary practice: the signing of the so called retention agreements related to contracts of sale, establishing that part of the pri- 
ce of the sale was to be retained. The purpose of such agreements was to pay off the seller's pending debts, and they could be signed under the condition that the retained part of the price be used to pay an outstanding debt between the seller and a third party alien to the sale. The acquisition of the object of the sale was postponed until the fulfillment of the condition or, failing that, until it was asecured. Additionally, given that Article 118 provided for the assumption of debt, the author will focus on assumption-of-debt agreements signed with the purpose of circumventing the complex procedure required by passive-subjective extinctive novation, which entailed the replacement of a given debt relation by a new one involving a new debtor. Article 118 also consolidates the discretionary power of the passive subject in credit/debit relations guaranteed by mortgages.

Palabras clave: Hipoteca; asunción de deuda; contrato de compraventa; pactos de retención o descuento

Key words: Mortgage, Assumption of Debt, Contract of Sale, Retention Agreement, Discount Agreement

Sumario: I. El poder de disposición del titular de la finca hipotecada: cuestiones previas sobre la transmisibilidad de la finca y los pactos de retención o descuento en el contrato de compraventa. II. La distinción entre novatio y asunción de deudas en el código suizo de las obligaciones de 1911: La adquisición de finca hipotecada y la transmisión de deuda garantizada según el código de Zurich. III. La redacción del artículo 118 de la Ley Hipotecaria española: la sucesión singular de las deudas garantizadas con derecho real limitado. IV. Transmisión de finca hipotecada: el doble ámbito de responsabilidad: 1) Preliminares: la reconocida influencia germánica en la reforma de 1946; 2) Responsabilidad personal y responsabilidad real dimanantes de préstamo garantizado con el derecho real limitado de hipoteca: retención del precio por el comprador; 3) Asunción de deuda y negocios onerosos transmisión de finca hipotecada: apuntes y notas jurisprudenciales. V. Reflexiones conclusivas. VI. Bibliografía.

\section{EL PODER DE DISPOSICIÓN DEL TITULAR DE LA FINCA HIPOTECADA: CUESTIONES PREVIAS SOBRE LA TRANSMISIBILIDAD DE LA FINCA Y LOS PACTOS DE RETENCIÓN O DESCUENTO EN EL CONTRATO DE COMPRAVENTA}

Como es sabido, el largo proceso codificador civil español llevó 
consigo la aprobación previa de ciertas leyes especiales ${ }^{1}$. En particular, en 1861 sería sancionada la Ley hipotecaria y, con ella y en favor del deudor y titular del patrimonio inmobiliario dado en garantía, se incluiría cierto margen y poder de disposición sobre la cosa. En buena lógica, de lo dicho se deduce que sólo a partir de entonces sería posible la transmisión de la cosa, bien o derecho sobre el que pesase la responsabilidad personal de la deuda garantizada.

Con todo, no se olvide que aún no se había previsto la limitación de la responsabilidad hipotecaria a un bien específico, por lo que todavía no se había consolidado el denominado -con mejor o peor acierto- principio registral de especialidad ${ }^{2}$.

En su momento, el que sería artífice de la Ley Hipotecaria, Francisco de CÁRDENAS, obvió la regulación de los pactos atinentes a la deuda garantizada en los casos de venta de finca hipotecada. Pocos años antes de su aprobación, destacaba los vicios y defectos del régimen hipotecario, no haciendo expresión del caso objeto de análisis ${ }^{3}$.

${ }^{1} \mathrm{Vid}$., sobre la materia los trabajos publicados por la autora de estas líneas titulados, «Vivienda familiar y subrogación hipotecaria en tiempos de crisis: notas sobre los pactos internos entre codeudores solidarios», RCDI, mayo-junio, 2010; La asunción espontánea de deuda, Valladolid, Lex Nova, 2008 y la bibliografía allí citada; "La expromisión ante el pago del tercero y la cesión de contrato», Estudios jurídicos en Homenaje al Profesor Enrique Lalaguna Domínguez, Tomo primero, Alventosa y Moliner (Coords.), Universitat de Valencia, págs. 789 a 807; «Obligaciones novables: Examen de la expromisión y las relaciones contractuales, legales y extracontractuales», Libro Homenaje al Profesor Dr. D. Manuel Cuadrado Iglesias, Gómez Gálligo (Coord.), Tomo I, Registradores de España-Civitas-Thomson Reuters, Madrid, 2008, págs. 947 a 967; «Examen crítico de los fundamentos dogmáticos y jurisprudenciales de la expromisión y del artículo 1.205 del Código civil español (La vicenda modificativa, la sucesión singular de las deudas, el programa de la prestación y la aplicabilidad de ciertos principios contractuales», $A D C$, tomo LXI, fas. II, 2008, págs. 619 a 719; «La dottrina civilista spagnola e la successione a titolo particolare dei debiti» ( «La doctrina civil española ante la sucesión singular de las deudas»), Vita Notarile: esperienze giuridiche, Ano LX, Parte I, II e III, número 1, gennaio aprile, 2008, págs. 511 a 540.

${ }^{2}$ Vid., por todos a mi Maestro, LASARTE ÁLVAREZ, Principios de Derecho civil, 5, Derechos Reales y Derecho hipotecario, Madrid, 2010, 8ª ed., pág. 11, y la bibliografía allí citada.

${ }^{3}$ Desde el entendimiento del sistema hipotecario como un sistema de publicidad y especialidad en todas las hipotecas, CÁRDENAS resumía las cualidades de «un buen régimen hipotecario [que] debe asegurar y conciliar entre sí estos importantes intereses: $1^{\circ} \mathrm{El}$ cumplimiento de la obligacion á que va afecta la finca hipotecada: $2^{\circ}$ Que el tercero que la adquiera ó trate con el deudor por razon de ella, no pueda destruir ni afectar la seguridad de dicha obligacion anterior, ni ser engañado por el propietario, á fin de que sufra los perjuicios de la carga el que ha disfrutado sus ventajas (...) quiere esto decir, en otros términos, que la hipoteca no solo ha de producir obligacion entre el acreedor y el deudor, sino que debe obligar tambien al tercero, en cuanto se somete á las cargas de la finca gravada, si adquiere su propiedad ó algun derecho sobre ella» (De 
Sin embargo, la figura de la venta de finca hipotecada y el pacto expreso acerca de la transmisión de la relación obligatoria que el inmueble garantiza, fue recogiéndose en la praxis notarial. Apréciese que esta práctica no contravenía norma expresa alguna y en ausencia de otra previsión, los particulares no tenían inconveniente alguno en suscribirla. Con el tiempo y gracias a la reforma de la Ley Hipotecaria, de 30 de diciembre de 1944, se incorporaría el texto del todavía vigente artículo 118 sobre la transmisión de finca hipoteca ${ }^{4}$.

Por su parte, la citada reforma de 1944, añadiría un elemento adicional en favor de la sucesión singular de las deudas al tipificar las consecuencias jurídicas de la falta de consentimiento del acreedor hipotecario sobre el cambio de deudor en el crédito garantizado con el derecho real limitado de realización del valor.

En este punto, resulta útil recordar que la doctrina del momento ya era conocedora de la sustitución del sujeto pasivo en los casos de relaciones obligatorias garantizadas con hipoteca, en particular, del ideado por el sistema hipotecario suizo ${ }^{5}$. En él, el adquirente de la finca hipotecada, por el mero hecho de la adquisición, sustituye al deudor hipotecante en la obligación garantizada, el primitivo deudor se liberará si el acreedor hipotecario acepta el cambio de sujeto pasivo $^{6}$.

En cuanto a la Ley Hipotecaria, sí recogía aquellos pactos que afectasen extintiva o modificativamente al derecho de crédito garan-

los vicios y defectos más notables de la legislación civil de España, y de las reformas que para subsanarlas se proponen en el Proyecto de Código civil de 1851, Madrid, 1852, págs. 406 y 407).

${ }^{4}$ El artículo 118 de la Ley Hipotecaria, dice: «En caso de venta de finca hipotecada, si el vendedor y el comprador hubieren pactado que el segundo se subrogará no sólo en las responsabilidades derivadas de la hipoteca, sino también en la obligación personal con ella garantizada, quedará el primero desligado de dicha obligación, si el acreedor prestare su consentimiento expreso o tácito.- Si no se hubiere pactado la transmisión de la obligación garantizada, pero el comprador hubiere descontado su importe del precio de la venta, o lo hubiere retenido y al vencimiento de la obligación fuere ésa satisfecha por el deudor que vendió la finca, quedará subrogado éste en el lugar del acreedor hasta tanto que por el comprador se reintegre el total importe retenido o descontado" (vid., en la materia el trabajo crítico sobre este precepto de AMORÓS GUARDIOLA, «La publicidad registral de los préstamos hipotecarios. La transmisión de la finca hipotecada», en Hipotecas y seguridad jurídica, Madrid, 1991, págs. 10 a 66 ).

5 Vid., SERRANO SERRANO, El Registro de la Propiedad en el Código civil suizo, comparado con el Derecho español, Valladolid, 1934.

6 Vid., LEHR, Tratado de Derecho civil germánico ó alemán, considerado en sí mismo y en sus relaciones con la legislación francesa, por ALCALDE PRIETO, Madrid, 1878, pág. 269. 
tizado $^{7}$. De modo tal que todo hecho o convenio entre las partes que pueda modificar o destruir la eficacia de una obligación hipotecaria anterior, como pudiera ser el pago, la compensación, la espera, el pacto o promesa de no pedir, la novación y la transacción, no surtirían efecto contra tercero en tanto no figurasen en el Registro ${ }^{8}$.

Como señalamos, los pactos de retención en el precio de la compraventa eran muy frecuentes, y su finalidad no era otra que el pago de la deuda pendiente del vendedor o, incluso, con la condición de destinar la parte del precio retenido al pago de una deuda que el vendedor tiene con otro ajeno a la compraventa9 ${ }^{9}$ La adquisición de la cosa objeto de compraventa se posponía al cumplimiento de la condición o, en su defecto, a su afianzamiento.

A mayor abundamiento, algunos casos controvertidos llegaron tempranamente al Tribunal Supremo que tuvo ocasión de pronunciarse sobre esta materia así, la Sentencia del 29 de marzo de 1858 donde se discutía acerca de un contrato de compraventa con pacto de retención del precio. En este caso, el vendedor transmitía una finca al precio de cuatro mil libras barcelonesas, reteniendo de este importe la compradora mil quinientas para pagar un préstamo pendiente del vendedor. En esta ocasión, por aplicación de la Partida 3.28.46 la compradora, al no cumplir con la delegación de la deuda, no adquirió el dominio pleno al tratarse de una venta condicionada.

Años después, en 1883, el Tribunal Supremo de Berlín en un asunto sobre la materia que ahora se estudia, declaró que la cláusula de asunción de deudas suscrita entre el comprador y el vendedor de una finca sobre la que recae una garantía de carácter real, solo a las partes y entre ellas tiene valor. En definitiva, el acuerdo por el que el comprador asume la deuda pendiente del vendedor, no tiene otro efecto que el interno entre quienes hayan suscrito el convenio, resultando totalmente inoponible para el acreedor de la deuda o titular del

7 En el mismo sentido que el actual artículo 144, teniendo especial interés la mención expresa según la redacción de 1946 sobre la novación del contrato primitivo.

8 Vid., GALINDO Y ESCOSURA, Comentario a la Ley Hipotecaria, tomo IV, 1884, pág. 284; MORELL Y TERRY, Comentario a la Ley Hipotecaria, tomo IV, 1930, págs. 221 y 224. Vid., también los términos prevenidos en el artículo 111 del Reglamento Hipotecario.

9 En prueba de ello, los formularios de la época recogían tales pactos: así venta con el pacto de succedendo o la venta con el pacto de succedendo en la que parte del precio se paga al vendedor (vid., FALGUERA, Formulario completo de notaría, arreglada a la Ley hipotecaria y á la de Enjuiciamiento civil, revisada y aprobada por la Academia de notarios de este territorio, Barcelona, 1862, págs. 12 y sigs., $2^{\mathrm{a}}$ ed.). 
derecho de crédito, ya que no ha sido parte de dicho convenio y puede legítimamente desconocer el mencionado pacto ${ }^{10}$.

En resumidas cuentas, la práctica notarial y la propia redacción del artículo 144 de la Ley hipotecaria española, evidenciaban la relativa frecuencia en la que el deudor del crédito garantizado transmitía la cosa sobre la que recaía el derecho de hipoteca, con o sin conocimiento del acreedor hipotecario ${ }^{11}$.

\section{LA DISTINCIÓN ENTRE NOVATIO Y ASUNCIÓN DE DEUDAS EN EL CÓDIGO SUIZO DE LAS OBLIGACIONES DE 1911: LA ADQUISICIÓN DE FINCA HIPOTECADA Y LA TRANSMISIÓN DE DEUDA GARANTIZADA SEGÚN EL CÓDIGO DE ZURICH}

Este primer texto recogió, al estilo francés, la novatio como modo de extinción de las relaciones obligatorias, si bien con la peculiaridad de los efectos radicales que produce, ya que extingue no sólo la relación sobre la que opera, sino también con ella sus accesorios y sus excepciones ${ }^{12}$.

Como novedad frente al texto de 1881, reglamenta en título propio tanto la cesión de créditos como la asunción de deudas ${ }^{13}$. Por tanto, existe duplicidad de procedimientos por los que sustituir al deudor

${ }^{10}$ En este sentido para CLEMENTE DE DIEGO -que describe despaciosamente el proceso- esta es una de las evidencias preparatorias del tercer grado de la evolución que da como resultado la transmisión inter vivos de deudas [vid., Transmisión de las obligaciones según la doctrina y la legislación española y extranjera (La transmisibilidad de las obligaciones, Madrid, 1912, págs. 234 y sigs.]. Además y sobre la novación, SANCHO REBULLIDA, «La novación de las obligaciones en el Derecho español», RCDI, XXXVIII, 404-405, 1962, págs. 1 a 22; La novación de las obligaciones, Barcelona, 1964, monografía cuyo origen se remonta a la exposición oral del tercer ejercicio a cátedra, celebrado en julio de 1961; "Comentario a los artículos 1.203 a 1.213», en Comentarios al Código Civil y Compilaciones Forales, Madrid, 1991, págs. 593 a 792; «Comentario a los artículos 1.203 a 1.213», en Comentario del Código Civil, II, Ministerio de Justicia, Madrid, 1993, 2ª ed., págs. 294 a 318.

11 «Todo hecho o convenio entre las partes, que pueda modificar o destruir la eficacia de una obligación hipotecaria anterior, como el pago, la compensación, la espera, el pacto o promesa de no pedir, la novación del contrato primitivo y la transacción o compromiso, no surtirá efecto contra tercero, como no se haga constar en el Registro por medio de una inscripción nueva, de una cancelación total o parcial o de una nota marginal, según los casos».

12 BENREY publicó un estudio sobre la cesión de las deudas, comparando especialmente el B.G.B. con el, entonces, proyecto de Código civil suizo (vid., De la cession de dettes, Gèneve, 1910).

13 «Titre cinquième: De la cession des créances et de la reprise de dette». 
-vía extintiva y modificativa-. La diferencia reside en los efectos de ambas fórmulas.

Este procedimiento de asunción de deudas, simplifica la tradicional novatio, al estar desprovisto de los efectos extintivos que provoca el instituto romano. A tenor de los artículos 175, 176 y 177, la asunción de deudas se configura como contrato celebrado entre el asumente y el acreedor. La naturaleza jurídica de este convenio, deja paso a la determinación de los efectos, en particular, sobre el mantenimiento de las relaciones accesorias dependientes de la relación en la que se sustituye el sujeto. En cuanto a las excepciones derivadas de la deuda asumida, pasan a ser ostentadas del antiguo al nuevo deudor.

El Código también previene las consecuencias de la anulación del contrato de asunción de deudas que, excepto en lo que a terceros de buena fe se refiere, implica la reviviscencia de la identidad de la obligación, accesorios incluidos.

Igualmente contempla los supuestos relacionados con la sucesión de empresa y establecimientos con activo y pasivo patrimonial ${ }^{14}$, si bien ha de ser tenida en cuenta la actualización del Código en materia de asunción de un patrimonio o la transmisión de un establecimiento, ya que se ha dado nueva redacción al artículo 181, dedicado a estos supuestos, y ha sido derogado el artículo 182 por la Ley federal de 3 de octubre de 2003. Apréciese que, en definitiva, el legislador responde a los casos de insolvencia y las dificultades de los cambios en la fisonomía patrimonial de un sujeto ${ }^{15}$. Por fin y en lo

14 «Art. 181.1.- Celui qui acquiert un patrimoine ou une entreprise avec actif et passif devient responsable des dettes envers les créanciers, dès que l'acquisition a été portée par lui à leur connaissance ou qui'il l'a publiée dans les journaux. 2.- Toutefois, l'ancien débiteur reste solidairement obligé pendant trois ans avec le nouveau, ce délai court, pour les créances exigibles, dès l'avis ou la publication, et, pour, les autres créances, dès la date de leur exigibilité». El nuevo párrafo tercero dice: «La cession d'un patrimoine ou d'une entreprise appartenait à des sociétés commerciales, à des sociétés coopératives, à des associations, à des fondations ou à des entreprises individuelles qui sont inscrites au registre du commerce, este régie par les dispositions de la loi du 3 octobre 2003 sur la fusion». 4.- Les effets d'un semblable transfert de passif sont d'ailleurs les mêmes que ceux du contrat de reprise de dette proprement dit. En cuanto al antiguo artículo 182.1.- Lorsque deux entreprises fusionnent en se transférant réciproquement leur actif et leur passif, les créanciers de l'une et de l'autre ont les droits dérivant de la cession d'un patrimoine, et lé entreprise nouvelle réponde de tout le passif. 2.- Les mêmes effets s'attachent à la constitution d'une société en nom collectif ou en commandite, quant aux dettes de l'entreprise individuelle absorbée par la société», ha quedado por efecto de la Ley sin contenido.

15 Es la intención especial de la Ley federal mencionada, que lleva por significativo 
que se refiere a bienes hipotecados, se remite a las disposiciones especiales $^{16}$.

Por su parte, el Código de Zúrich, recogió en su artículo 815, antes de la aprobación del texto sobre las obligaciones, el supuesto de adquisición de finca hipotecada. En estos casos, en idéntico sentido como hace el B.G.B., el nuevo titular del bien gravado con un derecho real de esta naturaleza adquiere, al tiempo, la deuda pendiente, produciendo el efecto de la sustitución del deudor originario en la responsabilidad personal ${ }^{17}$.

Este supuesto era conocido por el legislador español; en particular gracias a la versión del texto de LEHR, obra que por cierto fue especialmente manejada para la elaboración del actual artículo 1.112 del Código civil ${ }^{18}$. Según la traducción de ALCALDE PRIETO, este caso del artículo 815 lograba de forma necesaria la sustitución del deudor, aun cuando ésta «es más difícil, pues no sólo está ligado á la otra parte interesada, sino que está obligado personalmente á realizar el objeto del contrato; y no depende de su exclusiva voluntad el que la obligación pese (sic) ó deje de pesar sobre un tercero» ${ }^{19}$.

\section{LA REDACCIÓN DEL ARTÍCULO 118 DE LA LEY HIPOTECARIA ESPAÑOLA: LA SUCESIÓN SINGULAR DE LAS DEUDAS GARANTIZADAS CON DERECHO REAL LIMITADO}

Coincidieron en el tiempo resoluciones judiciales y aportaciones doctrinales españolas en favor de la sucesión singular y los estudios preparatorios del nuevo Código civil italiano, así como la traducción de varios tratadistas y la difusión del pensamiento transalpino ${ }^{20}$. Se

título la de Ley sobre la fusión, escisión y transformación de un patrimonio, en vigor desde el 1 de julio de 2004 (RS. 221.3101).

16 «Art. 183.- Sont réservées les dispositions spéciales relatives à la reprise de dette en matière de partage successoral ou d'aliénation d'immeubles grevés de gages».

17 Vid., artículo 832 del Código suizo de 10 de diciembre de 1907 según el texto consolidado de 27 de diciembre de 2005, donde se prevé el supuesto de venta de finca hipotecada, así como la necesidad de concurrencia de un pacto expreso y por escrito para que dicha asunción de deuda garantizada, por parte del comprador, surta efectos para el acreedor que así lo ratifique.

18 Vid., PEÑA BERNALDO DE QUIRÓS, El Anteproyecto del Código civil español, Madrid, 1965, pág. 350.

19 LEHR, Tratado de Derecho civil germánico, Madrid, 1878, pág. 268.

20 Vid., MORETÓN SANZ, «Examen crítico de los fundamentos dogmáticos y jurisprudenciales de la expromisión y del artículo 1.205 del Código civil español (La 
puede afirmar que el nuevo Código civil italiano ${ }^{21}$, tuvo un indudable valor preparatorio de la modificación de nuestra Ley Hipotecaria a la que acompaña hasta su aprobación.

Como decimos, estos hechos normativos coinciden y envuelven cronológicamente el iter legislativo de la reforma del año 1944 que incluyó, expresamente, el caso y las consecuencias de la transmisión de finca gravada con hipoteca y la susceptibilidad de la sucesión de la responsabilidad personal ${ }^{22}$.

Este nuevo artículo 118, también atribuiría relevancia y eficacia jurídica inter partes a los acuerdos a los que pudieren llegar los deudores, si bien la oponibilidad de dichos pactos quedaba reservada a los supuestos en que el acreedor prestase su aquiescencia al cambio pasivo.

Como es sabido y gracias a dicha previsión normativa, buena parte de la doctrina coetánea y también la propia jurisprudencia entendió que, definitivamente se había dado carta de naturaleza a la tipificación de la asunción de deudas. Se añadía así un renovado argumento en favor de la sucesión singular de las relaciones obligatorias $^{23}$, con el valor irrefutable de tratarse de derecho de directa aplicación.

Por otra parte, la reforma incorporaba otra institución interesante para el estudio como es el caso de la hipoteca de responsabilidad limitada, cuestión ésta que no presentó el mismo consenso doctrinal reverdeciendo, en este sentido, el debate sobre la transmisión de las deudas ${ }^{24}$.

vicenda modificativa, la sucesión singular de las deudas, el programa de la prestación y la aplicabilidad de ciertos principios contractuales», cit.; "La dottrina civilista spagnola e la successione a titolo particolare dei debiti», cit.

${ }^{21}$ Cuando llega el momento de la novación subjetiva pasiva, el artículo 1.235 remite a los términos prevenidos por el capítulo VI «De la delegación, de la expromisión y de la asunción», sin atribuir consecuencias prácticas a la distinción entre novación y sucesión en la deuda evitando, en suma, encuadrar estas figuras como instituciones novatorias. Por lo que a la erróneamente concebida por el Código civil español como novación subjetiva activa, se encuentra en el italiano en sede de cumplimiento y en particular bajo la denominación técnica "Del pagamento con surrogazione» (vid., artículos 1.210 a 1.215). Sistemáticamente la novación se integra, junto a la remisión, a la compensación, a la confusión y a la imposibilidad sobrevenida, entre los modos de cumplimiento distintos del pago (Cap. IV), frente a los fenómenos de la expromisión, asunción y delegación que sencillamente se integran en el Capítulo VI intitulado «Della delegazione, dell espromissione e dell accollo».

${ }^{22}$ Ley de Reforma Hipotecaria de 30 de diciembre de 1944.

${ }^{23} \mathrm{Vid}$., LA RICA Y ARENAL, "Comentarios a la Ley de Reforma Hipotecaria de 1944», Libro homenaje a Don Ramón DE LA RICA Y ARENAL, I, Madrid, 1976, pág. 147.

${ }^{24}$ El caso del artículo 140 de la Ley Hipotecaria, es decir, la hipoteca de responsabilidad limitada, excepciona los artículos 105 y 1.911 del Código civil. Los términos 
En todo caso, sobre este artículo que se acaba de transcribir y la hipoteca de responsabilidad limitada, la doctrina se divide en el tratamiento del cambio de deudor en los supuestos en que el titular del bien ejerza su poder de disposición. DÍEZ-PICAZO y GULLÓN no creen que cuando se transmite el bien hipotecado se produzca una asunción forzosa de la deuda ${ }^{25}$; por el contrario, otro nutrido sector sostiene la automaticidad del cambio de sujeto pasivo de la deuda entendido como un caso de subrogación legal ${ }^{26}$. Con todo, esta afirmación es difícil de cohonestar con las acciones que asisten al acreedor garantizado, distintas de la ejecución hipotecaria. Además, en defecto de pacto expreso serán de aplicación tanto la facultad resolutoria del 1.124 como la acción del 1.502 del Código civil, por lo que a la suspensión del pago del precio se refiere.

En suma y volviendo sobre la finca hipotecada, la doctrina sostenía que esta transmisión sobre un derecho real limitado circunscrito al bien, en exclusiva, implicaba por parte del adquirente, la asunción automática ope legis de la deuda ${ }^{27}$.

\section{TRANSMISIÓN DE FINCA HIPOTECADA: EL DOBLE ÁMBITO DE RESPONSABILIDAD}

\section{Preliminares: la reconocida influencia germánica en la reforma de 1946}

Son múltiples los elementos de interés recogidos tanto en la Ley

de aquel artículo 140 son los siguientes: «No obstante lo dispuesto en el artículo 105, podrá válidamente pactarse en la escritura de constitución de la hipoteca voluntaria que la obligación garantizada se haga solamente efectiva sobre los bienes hipotecados.- En este caso, la responsabilidad del deudor y la acción del acreedor, por virtud del préstamo hipotecario, quedarán limitadas al importe de los bienes hipotecados y no alcanzarán a los demás bienes del patrimonio del deudor.- Cuando la hipoteca así constituida afectase a dos o más fincas y el valor de alguna de ellas no cubriese la parte del crédito de que responda, podrá el acreedor repetir por la diferencia exclusivamente contra las demás fincas hipotecadas, en la forma y con las limitaciones establecidas en el artículo $121 »$.

${ }^{25}$ Vid., Sistema de Derecho Civil III, 2, Madrid, $8^{\text {a }}$ ed., pág. 189.

26 Vid., ROCA SASTRE, Derecho Hipotecario, IV, Barcelona, págs. 192 y sigs., AMORÓS GUARDIOLA, «La publicidad registral de los préstamos hipotecarios. La transmisión de la finca hipotecada», en Hipotecas y seguridad jurídica, Madrid, 1991, pág. 66.

${ }^{27}$ Aunque no sea éste su lugar, esta afirmación es más que dudosa, toda vez que la afección específica de la finca no impedirá su ejecución, sea quien sea el titular, por lo que el titular no deudor o tercer poseedor se verá forzado a pagar la deuda ajena o, en su caso, a desamparar la finca como tercer poseedor que es. 
Hipotecaria como, muy especialmente, en las modificaciones recibidas en los años 40 y vigentes al día de hoy. La mejor doctrina contemporánea señaló las influencias que afectaban al texto; así lo hizo en su momento CASTÁN quien, al prologar los Estudios Hipotecarios de Jerónimo GONZÁLEZ destacaba que éste, «merced, en gran parte, a su persistente esfuerzo, la Ley Hipotecaria que, a pesar del deseo de sus autores de respetar lo histórico y lo tradicional, suponía, con ciertas concesiones a nuestras ideas jurídicas nacionales, la introducción o recepción, muy impopular, de un Derecho extranjero» ${ }^{28}$.

Baste recordar que la mejor literatura jurídica discutió largamente acerca de estas reconocidas influencias de nuestra Ley Hipotecaria; como evidencia, RAMOS FOLQUES ${ }^{29}$ sostenía que el texto de $1861^{30}$ no era una copia de las leyes germánicas, por el contrario, para PASCUAL MARÍN ${ }^{31}$ la implantación del sistema instaurado por aquella Ley supuso una nueva recepción del derecho germánico en España ${ }^{32}$. Con todo y al margen de estas sugerentes cuestiones, lo cierto es que este artículo 118 de la Ley Hipotecaria, tuvo innegables consecuencias para la directa aceptación de la denominada asunción deuda y el debate doctrinal y jurisprudencial en materia de sucesión de deudas.

\section{Responsabilidad personal y responsabilidad real dimanantes de préstamo garantizado con el derecho real limitado de hipoteca: retención del precio por el comprador}

La transcendencia, importancia y número de fincas hipotecadas de nuestro país no necesita ser encomiada: dada cuenta de las cuestiones prácticas que plantea, así como las consecuencias del doble sistema de responsabilidad personal e hipotecario que impone la sumi-

${ }^{28}$ CASTÁN TOBEÑAS, «La personalidad, la metodología y la obra de Jerónimo GONZÁLEZ Y MARTÍNEZ», prólogo en Estudios de Derecho Hipotecario y de Derecho Civil, Madrid, 1948, pág. XXII.

29 Op. cit., nots. 29 y 30.

30 Esta norma no recibió la preceptiva e íntegra publicación en la Gaceta, según las Reales órdenes de 22 de septiembre de 1836, 4 de mayo de 1838 y 9 de marzo de 1851. Antes bien, de la Ley Hipotecaria de 8 de febrero de 1861, únicamente fue insertada la ley de autorización para su publicación. Se razonaba después que vista su extensión, parecía más aconsejable su publicación por separado (vid., ORTIZ DE ZÚÑIGA, Jurisprudencia civil de España, Madrid, 1869, pág. 16).

31 Vid., Introducción al Derecho Registral.

32 Vid., LÓPEZ Y LÓPEZ, «Código y leyes especiales: reflexiones sobre la llamada descodificación», Centenario del Código civil (1889-1989), II, cit., págs. 1.163 a 1.175. 
sión de un bien de aquella naturaleza a una garantía real, la doctrina se ha ocupado intensamente de esta disciplina ${ }^{33}$.

Pues bien, teniendo en cuenta las aportaciones doctrinales señaladas, la Ley Hipotecaria de 1861 fue objeto de modificaciones par-

${ }_{33}$ Así, sobre responsabilidad personal/patrimonial/hipotecaria, vid., GONZÁLEZ PALOMINO, «La adjudicación para pago de deudas», Estudios jurídicos de arte menor, I, Navarra, 1964. (Publicada también esta Conferencia desarrollada en la Academia Matritense del Notariado el 22 de marzo de 1943 en Anales de la Academia Matritense del Notariado, I, 1945); SANZ FERNÁNDEZ, "Compraventa de finca hipotecada. Conferencia impartida en el Colegio Notarial de Barcelona el 21 de Abril de 1944», Cuestiones de Derecho Hipotecario y Social, Barcelona, 1945, págs. 77 a 135; NÚÑEZ LAGOS, «La obligación personal y la responsabilidad real en las nuevas modalidades de hipoteca», $R G L J$, XCII, 181, 1947, págs. 61 a 79; RICA Y ARENAL, «La obligación personal y la responsabilidad real en las nuevas modalidades de hipoteca», AAMN, IV, 1948, págs. 281 a 327; ROCA SASTRE y PUIG BRUTAU, «Responsabilidad por débito ajeno», en Estudios de Derecho Privado. I. Obligaciones y Contratos, Madrid, 1948, págs. 188 a 197; CABELLO DE LA SOTA, «La hipoteca en garantía de renta y prestaciones periódicas: Sus problemas», $A A M N$, V, 1950, págs. 83 a 171; FERNÁNDEZ DE VILLAVICENCIO ARÉVALO, «La facultad de disposición», ADC, III, IV, 1950, págs. 1025 a 1056; JORDANO BAREA, «Asunción de deuda. Comentario a la Sentencia del Tribunal Supremo de 10 de febrero 1950», ADC, III, IV, 1950, págs. 1379 a 1380; ALONSO FERNÁNDEZ, «El débito y la responsabilidad», Información Jurídica, 107, 1952, págs. 341-366. (Publicado también en Curso de Conferencias sobre Derecho Inmobiliario Registral, Madrid, s.f., pero 1951-952, págs. 1 a 26); ALBALADEJO GARCÍA, «La responsabilidad de los herederos por deudas del causante, antes de la partición», $A D C, \mathrm{XX}$, III, 1967, págs. 479 a 513; VALLET DE GOYTISOLO, «La responsabilidad patrimonial universal y las garantías personales y reales», Panorama del Derecho Civil, Barcelona, 1973, $2^{\mathrm{a}}$ ed, págs. 221 a 240; CERVERA, «En torno al futuro de la novación», en Estudios jurídicos en homenaje al Profesor Federico de CASTRO, Madrid, 1976, págs. 451 a 474; TORRES ESCÁMEZ, «La hipoteca de finca vendida», $R D P, 1983$, págs. 917 a 925; GONZÁLEZ GARCÍA, Responsabilidad del heredero y derechos de los acreedores sobre el patrimonio hereditario, Madrid, 1989; AMORÓS GUARDIOLA, «La publicidad registral de los préstamos hipotecarios. La transmisión de la finca hipotecada», en Hipotecas y seguridad jurídica, Madrid, 1991, págs. 10 a 66; GÁLVEZ CRIADO, "Contrato de asunción de deuda: inexistencia del consentimiento del acreedor. Efectos de este contrato (Comentario a la Sentencia del Tribunal Supremo de 30 de junio de 1996)», ADC, L, III, 1997, págs. 1547 a 1556; MARTÍNEZ-GIL VICH, «Algunos aspectos de la cesión de créditos y de la asunción de deudas. Conferencia pronunciada en la Academia Matritense del Notariado el 3 de abril de 1997», AAMN, XXXVIII, 1998, págs. 225 a 256; CASTILLO MARTÍNEZ, Responsabilidad personal y garantía hipotecaria, Pamplona, 1999; BENDITO CAÑIZARES, "Comentario al artículo 118 de la LH» en Comentarios al Código Civil y compilaciones forales, ALBALADEJO y DÍAZ ALABART (Dirs.), Madrid, 2000; CASTILLO MARTÍNEZ, "Adquisición de finca hipotecada en fase de ejecución (Comentario a la Sentencia del Tribunal Supremo de 30 de enero de 1999)», RDP, abril, 2000, págs. 308 a 348; HERBOSA MARTÍNEZ, La Asunción de Deuda garantizada con hipoteca (Actualizada a la Ley 1/2000, de 7 de enero, de Enjuiciamiento Civil, Madrid, 2001; ORTIZ RODRÍGUEZ, José, «La responsabilidad del heredero por deudas y legados», Homenaje a Antonio HERNÁNDEZ GIL, III, Madrid, 2001, págs. 2561 a 2584. 
ciales, como las de 1903 y 1909 si bien, finalmente, el alcance de la producida en 1944 devino en inevitable la aprobación del Texto refundido de 1946.

En particular, fue la Ley de reforma de 30 de diciembre de 1944, la que incorporó al texto legal el artículo 118, en su párrafo primero, supuesto por otra parte que daba carta de naturaleza a la práctica notarial en que consistía el hecho regulado. Como es sabido, estos pactos de retención en el precio de la compraventa han sido muy frecuentes bien para pagar la deuda pendiente del vendedor o incluso con la condición de destinar la parte del precio retenido al pago de una deuda que el vendedor tiene con otro ajeno a la compraventa. La adquisición de la cosa objeto de compraventa se posponía al cumplimiento de la condición o, en su defecto a su afianzamiento.

En este sentido, la Sentencia del Tribunal Supremo de 29 de marzo de 1858 , recogía un supuesto de compraventa con pacto de retención del precio: el vendedor transmitía una finca al precio de cuatro mil libras barcelonesas, reteniendo de este importe la compradora mil quinientas para pagar un préstamo pendiente del vendedor. En esta ocasión, por aplicación de la Partida 3.28.46, la compradora al no cumplir con la delegación de la deuda, no adquirió el dominio pleno al tratarse de una venta condicionada ${ }^{34}$.

Como premisa mayor ya anunciada, conviene tener presente el dictado de la asunción de la deuda hipotecaria en el B.G.B., cuyo parágrafo 416 dice: «1.- Si el adquirente de una finca, mediante acuerdo con el enajenante, asume una deuda de éste que está garantizada mediante hipoteca sobre la finca, el acreedor sólo puede ratificar la asunción de la deuda si el enajenante le informa. Si han transcurrido seis meses desde la recepción de la comunicación, se considera que se ha concedido la ratificación, a menos que el acreedor se la haya denegado al enajenante dentro de dicho período de tiempo; la disposición del \& 415.2, inciso segundo, no se aplica.- 2.La notificación no puede ser realizada por el enajenante hasta después de que el adquirente haya sido inscrito en el Registro como propietario. Debe hacerse por escrito y contener una referencia del hecho de que la persona que asume la deuda ocupa el lugar del antiguo deudor a menos que el acreedor declare su negativa dentro de un período de seis meses.- 3.- El enajenante notificará al acreedor, previa petición del adquirente, la asunción de la deuda. Tan pronto

${ }^{34}$ Vid., CASTILLO MARTÍNEZ, Responsabilidad personal y garantía hipotecada, cit., pág. 254. 
como se resuelva la cuestión de la ratificación el enajenante se lo notificará al adquirente».

Contrástese la regulación que se acaba de transcribir, con las influencias que inspiraban a la mejor doctrina, extremo que se evidenció incluso en los debates parlamentarios que precedieron a la aprobación del Código civil ${ }^{35}$. Esta importación doctrinal se encarna en la figura de Jerónimo GONZÁLEZ ${ }^{36}$ gran conocedor del Derecho alemán ${ }^{37}$. En este sentido, como decimos CASTÁN TOBEÑAS advertía que «se habrá de revisar, quizá, algún día la tendencia germanista y de supervaloración del Derecho extranjero que parece animar la obra de D. Jerónimo González, cuando menos en su aspecto técnico -aunque ya ha sido atenuada y rectificada, en muchos puntos, por el propio autor-para dar paso a orientaciones más respetuosas con la realidad jurídica, con nuestras tradiciones y con nuestro espíritu ${ }^{38}$.

Pues bien, los contenidos del párrafo segundo del artículo 118, entre otras cuestiones relativas a los problemas de obligación personal y derecho real de hipoteca ${ }^{39}$, fueron incorporadas gracias al texto refundido de 1946, siendo en general bien recibida por la doctrina y entendida como uno de los supuestos que admite la transmisión del débito.

En resumidas cuentas se pude afirmar, sin temor al exceso, el 118 de la LH tiene la transcendencia de «consagrar legislativamente la asunción de deudas sin acudir al procedimiento de la novación» ${ }^{40}$.

35 Así vid., las alegaciones de AZCÁRATE sobre la causa y su inutilidad (Congreso 9 de abril de 1889, número 90).

${ }^{36}$ En este sentido, el prólogo escrito por CASTÁN TOBEÑAS, decía, «todavía mayor fascinación (que el método constructivo), ejerció sobre el maestro la dirección de la llamada escuela tubingense de Derecho privado o de la jurisprudencia de intereses» («La personalidad, la metodología y la obra de don Jerónimo González», a la edición de los Estudios de Derecho hipotecario y Derecho civil, publicada por el Ministerio de Justicia, 1948, tomo I, especialmente págs. XV y sigs.).

37 Este jurista formaba parte de la Junta de Fiscales, según consta en el Anuario de la DGR de 1922 (Madrid, 1923); formó parte del Tribunal Supremo, ocupando en 1935 la presidencia de la Sala primera. Además fue el fundador en 1925, de la Revista Crítica de Derecho Inmobiliario, revista que también dirigió.

38 Ibidem, pág. XXIV.

39 Tres modalidades, según NÚÑEZ LAGOS: a) la hipoteca de responsabilidad limitada; b) la hipoteca en garantía de rentas y prestación periódicas y c) subrogación o reversión de hipoteca regulada en el párrafo final del artículo 118 (vid., «La obligación personal y la responsabilidad real en las nuevas modalidades de hipoteca», cit., pág. 73).

40 Vid., ROCA SASTRE y PUIG BRUTAU, «La transmisión pasiva de las obligaciones», cit., pág. 320 . 


\section{Asunción de deuda y negocios onerosos transmisión de finca hipotecada: apuntes y notas jurisprudenciales}

Pues bien, los pactos de retención y descuento previstos por el artículo 118 de la vigente Ley Hipotecaria no excluyen la suscripción de otros distintos, siempre y cuando si lo que se pretende es la liberación del deudor primitivo y vendedor de la finca hipotecada, se dé cuenta de ellos al acreedor ${ }^{41}$.

En este sentido, la Sentencia del Tribunal Supremo de 1 de septiembre de 2004, declara que «las partes de un contrato de venta de fincas hipotecadas pueden, en ejercicio de su potencialidad normativa creadora (artículo 1.255 del Código Civil), pactar distintos medios o expedientes para lograr la satisfacción del crédito del vendedor. A algunos se refiere el artículo 118 de la Ley Hipotecaria, cuyo primer apartado regula precisamente aquel que ha mencionado el comprador recurrente como efectivamente convenido: el comprador se coloca en la posición deudora que corresponde al vendedor en la relación de obligación garantizada con la hipoteca, con consecuencia liberatoria para este último. Es claro que, en ese caso, no basta con que los dos contratantes se pongan de acuerdo en que tenga lugar el cambio subjetivo en la posición pasiva de la relación de obligación, ya que es necesario también que el acreedor lo consienta (artículo 1205 del Código Civil) $\gg^{42}$.

La aplicabilidad de estas previsiones del artículo 118 de la Ley Hipotecaria, no se circunscribe a la transmisión producida por contrato de compraventa. En este punto, téngase en cuenta que nada impide su integración analógica al usufructo voluntario: así en un usufructo constituido por actos inter vivos, el usufructuario puede haber asumido la deuda que garantizaba la hipoteca anterior ${ }^{43}$, en cuyo caso el deudor primitivo quedaría desligado si el acreedor con-

41 Vid., VIATTE, «La transmission de 1 hypoteque sans la créance garantie», Gaz. Pal., 2, 1975, Doctr., págs. 513 a 514.

${ }^{42}$ En todo caso, y por lo que al Impuesto sobre Bienes Inmuebles la Sentencia de 24 de enero de 2004 de la Sala tercera del Tribunal Supremo ha fijado la siguiente doctrina legal «en el supuesto de cambio, por cualquier causa, en la titularidad de los derechos objeto del Impuesto de sobre Bienes Inmuebles, no es precisa la declaración de fallido del adquirente o los adquirentes intermedios para que, declarada la del deudor originario transmitente de los bienes afectos al pago de la deuda tributaria, pueda derivarse la acción contra dichos bienes tras la notificación reglamentaria, al adquirente y titular actual de los mismos, del acto administrativo de derivación».

43 Vid., HUC, Traité théorique et pratique de la cession et de la transmission de créances, tome I, Paris, 1891, pág. 321. 
siente $^{44}$. Idénticas cuestiones se reproducirán en otras transmisiones de carácter oneroso. La limitación de espacio será respetada, si bien no puede omitirse que el pacto que medie entre los codeudores puede calificarse rectamente como delegación siquiera también se observe el contenido del artículo 1.205 del Código civil ${ }^{45}$.

Pese a ciertas cuestiones criticables sobre la precisión terminológica que merece la inclusión de la denominada «subrogación», el precepto estima innegociable el consentimiento del acreedor. Cuestión esta última que en nada empece al respeto que merezcan los pactos entre codeudores y la denominada asunción acumulativa interna inoponible, en buena lógica, al titular del derecho de crédito.

Retomando la dispersión terminológica, «quizá la confusión padecida por algunos autores arranca de la propia promiscuidad que el legislador y la doctrina hipotecarias manifiestan al usar el término 'subrogación'. Así, en el art. 118, I Lh se denomina subrogación en la obligación garantizada con la hipoteca al efecto producido por la asunción de deuda pactada entre el adquirente de una finca hipotecada y el deudor hipotecante que ahora la enajena. Y, sin embargo, pese al empleo de la palabra 'subrogación', estamos lejos, en el plano del régimen jurídico de la subrogación por pago. En el art. 118 , I Lh el legislador, coherentemente, exige, para que deudor hipotecante quede liberado de su vínculo con el acreedor, que éste preste su consentimiento a dicho pacto de asunción, expreso o tácito, lo que perfectamente concuerda con el citado artículo 1205 C.c» ${ }^{46}$.

En el interesante supuesto ventilado por la Resolución de la Dirección General de los Registros y del Notariado, de 2 de diciembre de 1999, los propietarios de las fincas embargadas antes de que se hayan adjudicado a tercero instan la cancelación de la hipoteca y el derecho de subrogación. Denegada la inscripción, la Dirección General desestima el recurso advirtiendo que: « 2 . La venta de una finca hipotecada no tiene, por sí, el efecto de que con la finca se trasmita

${ }^{44}$ Vid., GARCÍA CANTERO, "Comentario al artículo 509», en Comentario del Código Civil, I, Madrid, 1991, págs. 1.352. Téngase presente, además, MARCO MOLINA, op. cit., pág. 171 y el artículo 144 de la LH y del RH el 240.

45 En cuanto a la publicidad registral, vid., el artículo 230 del Reglamento hipotecario que advierte que «pagada por el deudor que vendió la finca hipotecada la deuda asegurada con la hipoteca en el caso previsto en el párrafo segundo del artículo 118 de la Ley, será título bastante para hacer constar en el Registro la subrogación establecida en este precepto, el acta de entrega o la escritura de carta de pago en que el vendedor manifieste que hace uso de dicha subrogación».

${ }_{46}$ RUBIO GARRIDO, La Ley de subrogación y modificación de préstamos hipotecarios, Granada, 1998, pág. 69, nt. 112. 
también al comprador la deuda garantizada con la hipoteca de modo que el deudor quede ya liberado de esta deuda. Para conseguir este efecto sería necesario, además del consentimiento del nuevo deudor (el pacto por el que se establezca que el comprador "se subrogará no sólo en las responsabilidades derivadas de la hipoteca, sino también en la responsabilidad con ella garantizada"), el consentimiento expreso o tácito del acreedor (cfr. artículos 118.1 de la Ley Hipotecaria y 1.205 del Código Civil). De no darse este doble consentimiento, el deudor seguirá estando sujeto a la deuda no obstante haberse trasmitido la finca hipotecada, e incluso en el caso de que el comprador, por haberse comprometido frente al vendedor al pago de la deuda o por cualquier otra razón, hubiere descontado del precio el importe de la obligación garantizada o hubiere retenido este importe. Y es precisamente para esta hipótesis para la que el artículo 118.1 de la Ley Hipotecaria prevé una especial subrogación en favor del deudor: Si "al vencimiento de la obligación fuere ésta satisfecha por el deudor que vendió la finca (la venta precede pues al pago y, no obstante la venta, el vendedor sigue siendo el deudor), quedará subrogado éste en lugar del acreedor hasta tanto que el comprador se le reintegre el total importe retenido o descontado". 3. El artículo 231 del Reglamento Hipotecario no crea una especial hipótesis de subrogación -lo que sólo sería posible por vía de Ley- sino que se limita a aclarar que la especial subrogación que, conforme al artículo 118.1 de la Ley Hipotecaria, se produce en favor del deudor cuando paga después de vendida la finca, se produce también cuando la transmisión de la finca hipotecada haya ocurrido en operaciones, a estos efectos, análogas a la venta, como son el remate y la adjudicación en pago. En el caso de que se ejecute una finca gravada con hipotecas o cargas preferentes al crédito del actor, se entiende que el rematante o adjudicatario acepta estas cargas y que, frente al deudor o dueño de la finca gravada, asume "la obligación de satisfacerlas"».

Baste con reiterar lo apuntado sobre que puede operar, de modo autónomo, una doble esfera de relaciones: la que se deduzca de la relación obligatoria principal y la que opera consecuencia de la garantía hipotecaria. Así lo ratifica el supuesto de hecho que ventila la Sentencia, fechada el 20 de junio de 2008, siendo Ponente MONTÉS PENADÉS: «En el caso, el codemandado D. Luis Antonio, marido de la también demandada $\mathrm{D}^{\mathrm{a}}$ María Dolores, adquirió un inmueble verificando un pago inicial mínimo del precio, más el IVA de la operación, y subrogándose en la hipoteca que gravaba el inmueble para pago del resto del precio. La adquisición se produce 
para la sociedad de gananciales, según declara el propio comprador, y así se inscribe en el registro de la Propiedad, al amparo del artículo 93.4 del Reglamento Hipotecario. En el momento de la adquisición, el matrimonio se rige por la sociedad de gananciales. Poco después, otorgan los cónyuges capitulaciones matrimoniales y liquidan la sociedad de gananciales. No figuran el bien adquirido, ni la hipoteca que lo grava, en el inventario. La hipoteca se ejecuta y, no alcanzando el precio de remate a cubrir la totalidad del crédito hipotecario, se reclama ahora frente a ambos cónyuges la parte no cubierta. La esposa opone que no intervino en la operación, que fue privativa del marido, así como que la adquisición del bien se produjo para el patrimonio privativo del marido y, en definitiva, que no responden los bienes gananciales de la deuda contraída para la adquisición del bien».

De modo, que «en el caso de autos ocurre que el negocio concreto de adquisición se aproxima a la adquisición de un bien a precio aplazado, que en este supuesto está además asegurado con un derecho (real) de garantía y genera dos órdenes de efectos, unos en cuanto a la adquisición y condición del bien y otro en cuanto al carácter de la deuda contraída o, más exactamente, asumida».

\section{REFLEXIONES CONCLUSIVAS}

Sabido es que la Ley de reforma de la Ley Hipotecaria de 30 de diciembre de 1944, incorporó al texto legal el artículo 118, que a su vez conservó idéntica numeración con la refundición del año 46. Este precepto, en su párrafo primero, consagró la práctica notarial de los pactos de retención en el precio de la compraventa, muy frecuente para pagar la deuda pendiente del vendedor, o con la condición de destinar la parte del precio retenido al pago de una deuda que el vendedor tiene con otro ajeno a la compraventa. La adquisición de la cosa objeto de compraventa se posponía al cumplimiento de la condición o, en su defecto a su afianzamiento.

Con la mejor doctrina, se ha de convenir que el artículo 118 de la Ley Hipotecaria dio carta de naturaleza a la asunción de deudas prescindiendo, gracias a la fórmula tipificada, del complejo procedimiento de la novación subjetiva pasiva extintiva que reclamaba la sustitución de una relación por otra nueva a la que reemplazaba.

Al tiempo, ratifica la esfera del poder de disposición que conserva el sujeto pasivo del derecho de crédito garantizado con hipoteca. En definitiva, éste -caso de que sea el titular del bien en cuestión- podrá 
transmitir, como no podía ser de otra manera, el bien inmueble sujeto al derecho real limitado de realización de valor. Y podrá transmitir tanto el bien inmueble, mediante el oportuno negocio en que se pueda pactar la retención o descuento de parte del precio, como la relación obligatoria sometida, esta sustitución pasiva, a la aquiescencia tácita o expresa del titular del derecho de crédito. Este último extremo, como es evidente, reitera la doctrina tradicional e incólume del Código civil sobre el consentimiento preceptivo del acreedor para los supuestos de cambio de sujeto pasivo.

Aborda también el artículo 118 de la Ley Hipotecaria, al prever sus consecuencias, que el sujeto activo del derecho de crédito no autorice o no se le haya comunicado tal pretensión de sustitución pasiva, confirmando el doble ámbito de responsabilidades que se pueden deducir de este instituto, como son las personales deducidas de la relación obligatoria principal y las reales, consecuencia del derecho real limitado y accesorio de aquélla. Sin duda, el fenómeno es de una riqueza práctica necesitada de la sucesiva doctrina jurisprudencial que ha perfilado algunas de sus cuestiones más controvertidas.

\section{BIBLIOGRAFÍA}

Además de la citada a pie:

AMORÓS GUARDIOLA, «La publicidad registral de los préstamos hipotecarios. La transmisión de la finca hipotecada», en Hipotecas y seguridad jurídica, Madrid, 1991, págs. 10 a 66.

BENREY, De la cession de dettes, Gèneve, 1910.

CÁRDENAS, De los vicios y defectos más notables de la legislación civil de España, y de las reformas que para subsanarlas se proponen en el Proyecto de Código civil de 1851, Madrid, 1852.

CASTÁN TOBEÑAS, «La personalidad, la metodología y la obra de Jerónimo GONZÁLEZ Y MARTÍNEZ», prólogo en Estudios de Derecho Hipotecario y de Derecho Civil, Madrid, 1948.

CASTILLO MARTÍNEZ, Responsabilidad personal y garantía hipotecaria, Pamplona, 1999.

DE DIEGO, Transmisión de las obligaciones según la doctrina y la legislación española y extranjera (La transmisibilidad de las obligaciones), Madrid, 1912. 
DÍEZ PICAZO y GULLÓN, Sistema de Derecho Civil III, 2, Madrid, $8^{\mathrm{a}}$ ed.

FALGUERA, Formulario completo de notaría, arreglada a la Ley hipotecaria y á la de Enjuiciamiento civil, revisada y aprobada por la Academia de notarios de este territorio, Barcelona, 1862, $2^{\mathrm{a}}$ ed.

GALINDO Y ESCOSURA, Comentario a la Ley Hipotecaria, tomo IV, 1884.

HUC, Traité théorique et pratique de la cession et de la transmission de créances, tome I, Paris, 1891

LASARTE ÁLVAREZ, Principios de Derecho civil, 5, Derechos Reales y Derecho hipotecario, Madrid, 2010, $8^{\text {a }}$ ed.

LEHR, Tratado de Derecho civil germánico ó alemán, considerado en sí mismo y en sus relaciones con la legislación francesa, Madrid, 1878.

LÓPEZ Y LÓPEZ, «Código y leyes especiales: reflexiones sobre la llamada descodificación», Centenario del Código civil (1889-1989).

MORELL Y TERRY, Comentario a la Ley Hipotecaria, tomo IV, 1930.

ORTIZ DE ZÚÑIGA, Jurisprudencia civil de España, Madrid, 1869.

PEÑA BERNALDO DE QUIRÓS, El Anteproyecto del Código civil español, Madrid, 1965.

LA RICA Y ARENAL, "Comentarios a la Ley de Reforma Hipotecaria de 1944», Libro homenaje a Don Ramón DE LA RICA Y ARENAL, I, Madrid, 1976.

ROCA SASTRE, Derecho Hipotecario, $I V$, Barcelona.

SANCHO REBULLIDA, «La novación de las obligaciones en el Derecho español», RCDI, XXXVIII, 404-405, 1962, págs. 1 a 22; La novación de las obligaciones, Barcelona, 1964.

- «Comentario a los artículos 1.203 a 1.213», en Comentarios al Código Civil y Compilaciones Forales, Madrid, 1991, págs. 593 a 792.

— «Comentario a los artículos 1.203 a 1.213», en Comentario del Código Civil, II, Ministerio de Justicia, Madrid, 1993, 2ª ed., págs. 294 a 318.

SERRANO SERRANO, El Registro de la Propiedad en el Código civil suizo, comparado con el Derecho español, Valladolid, 1934.

VIATTE, «La transmission de 1 hypoteque sans la créance garantie», Gaz. Pal., 2, 1975, Doctr., págs. 513 a 514. 


\section{VII. ÍNDICE DE RESOLUCIONES JUDICIALES CITADAS}

\section{Tribunal Supremo}

Sentencia de 29 de marzo de 1858.

Sentencia de 10 de febrero 1950.

Sentencia de 30 de junio de 1996.

Sentencia de 30 de enero de 1999.

Sentencia de 1 de septiembre de 2004.

Sentencia de 20 de junio de 2008. 
